\title{
Prevalence and socioeconomic determinants of leisure time physical activity among Polish farmers
}

\author{
Elżbieta Biernat ${ }^{1}$, Monika Piątkowska², Władysław Mynarski ${ }^{3}$ \\ ${ }^{1}$ Warsaw School of Economics, Poland \\ 2 Josef Pilsudski University of Physical Education in Warsaw, Poland \\ ${ }^{3}$ The Jerzy Kukuczka Academy of Physical Education in Katowice, Poland
}

Biernat E, Piątkowska M, Mynarski W. Prevalence and socioeconomic determinants of leisure time physical activity among Polish farmers. Ann Agric Environ Med. 2018; 25(1): 151-156. doi: 10.26444/aaem/75927

\begin{abstract}
Introduction and objective. The aim of this study is to evaluate the leisure time physical activity of Polish farmers in the context of meeting health-related recommendations, and to diagnose the social and economic determinants. The analysis concerned leisure and transportation activities of various intensity and sedentary time.

Materials and method. Farmers $(n=153)$ aged over 18 were selected from a representative sample of Polish society $(n=2039)$. In order to evaluate LTPA, the long version of the IPAQ was used. Statistically significant differences between the variables were tested using non-parametric tests. The relationship between the amount of exercise recommended by the WHO and studied socio-demographic criteria was assessed using log-linear analysis.

Results. The WHO health recommendations were met by $33.3 \%$ of farmers. Shares in LTPA (19.1\%) and transportation (19.2\%) significantly increased the chance of achieving these norms ( $O R=12.54$ and 0.07 , respectively). Along with age ( $\geq 40$ years) and income ( $\geq 3000$ PLN/ 6750 ) of Polish farmers, the risk of insufficient physical activity increased. Average MET-min/week for LTPA was $299.8 \pm 583.4$ and transportation $-521.2 \pm 1973.9$. The average time of sitting during working days was 4.4 \pm 2.9 , while it was $4.5 \pm 3.2 \mathrm{hrs} /$ day during weekends.

Conclusions. Health-promoting changes are necessary among Polish farmers, including an increase in the awareness of health benefits and the necessity of undertaking physically active ways of spending leisure time. It seems to be a legitimate action to develop a mini-tourist trail in the rural environment as a means of promoting physical activity also among women aged over 40, and from lower income groups, who are especially threatened by inactivity.
\end{abstract}

\section{Key words}

farmers, LTPA, sedentary behaviour, health promotion, HEPA, WHO recommendations

\section{INTRODUCTION}

Modern rural areas are mechanised and automated [1]. Machines and equipment allow the performance of agricultural work, provide independence from atmospheric conditions, decrease losses in agricultural production and the number of employed and, most importantly, make work easier and more efficient. What is more, they more often save farmers from having to carry out physical work. Nowadays, no one can imagine a farm without a tractor, a harvester or planes for fertilisation and the protection of plants. One result of this situation is a noticeable decrease in the physical activity of farmers (larger even than in cities) [2], decreased fitness, and an increased incidence of diseases of affluence during the last decade [3]. A recent report from the Centers for Disease Control and Prevention indicates that physical inactivity is the highest in rural areas (37\%) and the lowest in urban areas (27\%), with some regional differences [4]. Similarly, evidence shows that Americans living in rural communities are more likely to be physically inactive, overweight and obese, compared to those living in urban locations [5]. Unfortunately, this also concerns young

Address for correspondence: Elżbieta Biernat, Warsaw School of Economics, Poland E-mail: elzbieta.biernat@sgh.waw.pl

Received: 18 July 2016; accepted: 9 May 2017; first published on July 20, 2017 people [6,7]. Inhabitants of rural areas are less interested in increasing their physical activity [8] and perceive themselves as less talented in work and less physically active than representatives of other professional groups [1]. Obviously, there are exceptions, like Chinese farmers [9] who still maintain an active lifestyle and are less obese than members of other groups. However, even among the Chinese, physical activities are more often replaced by sitting and watching TV (especially, during non-rural seasons) [3]. Similar observations were made in Australia, showing that people living in rural areas are 1.16 times more threatened by the risk of a sedentary lifestyle than those living in urban areas [2]. What is more, farmers in Australia are rarely regarded as outstandingly physically active due to the seasonal character of rural work and its mechanisation [10].

Researchers worldwide forecast a further decrease in physical activity in this professional group [3]. They also state that the character of farmers' work - seasonal, engaging small groups of muscles in a repetitive way, often in a constrained position and predominantly involving static effort - usually has a negative influence on the locomotor and circulatory systems [11]. Studies show that only about $10 \%$ of the employed population have a sufficient amount of dynamic aerobic activity, which can improve physical capacity, during working hours [11]. Also, the farming profession does not include a high enough proportion of physical activity for maintaining physical fitness and capacity. 
It is also necessary to stress that the large physical workload does not mean an improvement of physical fitness [12]. Due to this, it is recommended that physical activity should be increased during one's leisure time. Its character is different from activity related to professional work (various dynamic body movements, intensive efforts lasting for a relatively short period, interrupted with pauses for passive or active rest). Today, we are aware that only leisure time physical activity in the form of recreational training (with the intensity, duration and frequency recommended for health) can influence an increase in physical fitness and capacity and can bring substantial health benefits $[13,14]$.

Studies show that engagement in leisure time physical activity (LTPA) - regardless of the intensity of physical activity in work - decreases the risk of death caused by cardiovascular diseases (CVD) [15]. This phenomenon is observed both in the case of men and women. People who undertake LTPA at a moderate level live from 1.5 - 3.6 years longer than those who are less physically active at work. On the other hand, people of vigorous LTPA live longer than those who are moderately active by $2.6-4.7$ years [15]. However, studies indicate that people who perform hard professional work are rarely physically active in their leisure time [16].

\section{OBJECTIVE}

The aim of this study is to evaluate the leisure time physical activity of Polish farmers in the context of meeting healthrelated recommendations, and to make a diagnosis of its social and economic determinants. The analysis concerned leisure and transportation activities of varied intensity and sedentary time. It was assumed that analyses of this type (diagnosis of the level and determinants of LTPA of Polish farmers) can facilitate the programming of preventive activities to maintain farmers' capacity for professional work and their individual health.

\section{MATERIALS AND METHOD}

The surveys were conducted on a representative sample of Poles aged 15+ (3 - 7 April 2014 - Wave I - n=1019; 12 March,, 2015 - Wave II - n=1020) - using Computer-Assisted Personal Interviews (CAPI). The surveys were conducted by trained and supervised pollsters from GfK Polonia, who formulated questions in a way that was equally understandable for all respondents.

The respondents were selected according to set criteria on the basis of a representative demographic structure of the Polish population aged $15+$. This study presents only the results concerning farmers aged over 18 selected from the Poland-wide sample. A farmer was regarded as any person who runs (manufactures) a rural activity in the field of crop or animal production, including horticulture, pomiculture and fishery. The characteristics of the studied group $(n=153)$ are presented in Table 1 .

The research tool was the Polish long version of the International Physical Activity Questionnaire (IPAQ) [17]. Both in the first and second phase, respondents were asked about physical activity undertaken during their leisure time (including vigorous and moderate activity and walking during the last week), while moving from one place to another
Table 1. Socio-demographic characteristics of the sample $(n=153)$

\begin{tabular}{|c|c|c|c|}
\hline \multirow{2}{*}{ Factors } & & \multicolumn{2}{|c|}{ Total } \\
\hline & & $\mathrm{n}$ & $\%$ \\
\hline \multirow{2}{*}{ Gender } & Female & 96 & 62.5 \\
\hline & Male & 57 & 37.5 \\
\hline \multirow{5}{*}{ Age } & $18-29$ years old & 7 & 4.6 \\
\hline & 30-39 years old & 15 & 9.8 \\
\hline & $40-49$ years old & 26 & 17.2 \\
\hline & 50-59 years old & 35 & 22.9 \\
\hline & $>60$ years old & 70 & 45.5 \\
\hline \multirow{3}{*}{ Education } & Primary & 75 & 49.1 \\
\hline & Vocational & 66 & 43.1 \\
\hline & Secondary or higher & 12 & 7.9 \\
\hline \multirow{2}{*}{ Place of residence } & Village & 140 & 91.6 \\
\hline & City over 50 thous. inhabitants & 13 & 8.4 \\
\hline \multirow{4}{*}{$\begin{array}{l}\text { Average monthly gross } \\
\text { income (per capita in } \\
\text { household) }\end{array}$} & $<2,000 \mathrm{z} ł / \in 500$ & 35 & 22.9 \\
\hline & 2,000-2,999 PLN/ Є501-749 & 57 & 37.1 \\
\hline & 3,000- 4,499 PLN/€750-1124 & 42 & 27.6 \\
\hline & $\geq 4,500 \mathrm{PLN} / \in 1125$ & 19 & 12.4 \\
\hline \multirow{2}{*}{ Using the Internet } & Regularly or occasionally & 45 & 29.4 \\
\hline & Seldom or never & 108 & 70.6 \\
\hline
\end{tabular}

- walking or cycling (transportation). In accordance with the IPAQ methodology, only activity lasting individually longer than 10 minutes was taken into consideration [17]. In the second phase, an additional question was asked concerning the length of time spent sitting during weekends and during weekdays (hours/day).

On the basis of the collected data, the average energy expenditure of each activity (MET-min/week) was calculated by multiplying the MET assigned to it (vigorous - $8 \mathrm{MET}$, moderate - 4 MET, walking - 3.3 MET, cycling - 6.0 MET) by the number of days it was performed during a week, where MET corresponds to $\mathrm{O}_{2}$ consumption during rest and equals $3.5 \mathrm{ml} \mathrm{O}_{2} / \mathrm{kg}$ of the body mass per minute.

After a standard calculation of the time and frequency of the declared leisure time activities [17], the respondents were divided into those meeting and not meeting the prohealth activity level recommendations of the World Health Organisation (WHO) [13] - solely on the basis of leisure time activity. Those meeting the recommendations were persons undertaking moderate activities $\geq 150 \mathrm{~min} /$ week or vigorous $\geq 75 \mathrm{~min}$./week, or walking $\geq 150 \mathrm{~min} /$ week, or an equivalent of a combination of all leisure time activities, exceeding 600 MET-min/week.

Statistical calculations were conducted using IBM $^{\circ}$ SPSS $^{\circ}$ Statistics, version 21. In order to test the distribution of quantitative variables of physical activity a KolmogorovSmirnov (KS) test was applied. Due to lack of normality in further analyses of statistically significant differences between the variables, U Mann-Whitney, Kruskall-Wallis and Wilcoxon non-parametric tests were used. The relationship between the amount of exercise recommended by the WHO (moderate physical activity $\geq 150 \mathrm{~min} /$ week or vigorous physical activity $\geq 75 \mathrm{~min} /$ week, or the equivalent combination of moderate and vigorous activity) and the studied variables (gender, age $>40$ years, income $>3000$ PLN/€750, secondary or higher education, regularly or occasionally using the 
Internet, participation in LTPA and transportation activity) was assessed using log-linear analysis. The strength of the relationship was expressed by the odds ratio (OR) with a $95 \%$ confidence interval.

\section{RESULTS}

Participation in LTPA was declared by $39.2 \%$ of Polish farmers. The most common form was recreational walking (34.0\%), while vigorous (1.8\%) and moderate (8.7\%) activities were definitely more rare. The mean value of the total energy expenditure of recreational character was $299.8 \pm 583.4$ MET-min/week for the whole group of farmers, including walking - 204.8 $\pm 462.4 \mathrm{MET}$-min/week, vigorous activity - 14.2 \pm 117.4 MET-min/week and moderate activity 80.8 \pm 315.3 MET-min/week (tab. 2). In the case of moderate activities, it was relatively higher $\left(\mathrm{Chi}^{2}=11.0 ; \mathrm{p}<0.001\right)$ for farmers with incomes in the range of 3,000-4,499 PLN/€7501,124 (169.7 $\pm 405.1 \mathrm{MET}-\mathrm{min} /$ week) than in other income groups. Similarly, MET-min/week of moderate activities (197.0 \pm 524.0$)$ for persons regularly/occasionally using the Internet was substantially higher $($ Umann $=1934.5 ; \mathrm{p}<0.05)$ than in the "seldom" or "never" groups. The mean MET$\mathrm{min} /$ week for vigorous activities was highest $\left(\mathrm{Chi}^{2}=20.3\right.$; $\mathrm{p}<0.001)$ in the group of best educated farmers $(94.2 \pm 218.8$ MET-min/week). The mean MET-min/week of walking was related only with age $\left(\mathrm{Chi}^{2}=25.1 ; \mathrm{p}<0.001\right)$ - it was relatively higher in the youngest groups (aged 18-29 - 527.8 \pm 317.9 and 30-39-682.4 $\pm 877.9 \mathrm{MET}-\mathrm{min} /$ week). It must be noted that there is a high dispersion of results around mean values for moderate, vigorous activities and walking, indicating a large differentiation of physical activity parameters among the analysed group of farmers.
Transportation physical activity was declared by $43.9 \%$ of tested farmers (38.7\% on foot, $7.7 \%$ by bicycle). The mean value of the total energy expenditure for transportation physical activity of the whole analysed group was 582.9 \pm 1981.2 MET-min/week (Tab. 2). Walking resulted in energy expenditure in the order of 521.2 \pm 1973.9 MET-min/ week It should be mentioned that this value $(2562.1 \pm 4891.5$ MET-min/week) was significantly higher among farmers with the highest incomes $\left(\mathrm{Chi}^{2}=18.7 ; \mathrm{p}<0.001\right)$ than in other groups. As far as cycling transportation is concerned, mean energy expenditure of the whole group was 61.6 \pm 278.0 MET$\mathrm{min} /$ week, being relatively higher among representatives of the group of incomes of 3,000-4,499 PLN/€750-1,124 $\left(127.9 \pm 322.9 ; \mathrm{Chi}^{2}=8.9 ; \mathrm{p}<0.05\right)$.

Mean sedentary time was $4.4 \pm 2.9$ during weekdays and 4.5 $\pm 3.2 \mathrm{hrs} /$ day at weekends (Tab. 2). Analyses revealed a relationship between time spent sitting during weekdays, the age of respondents $\left(\mathrm{Chi}^{2}=19.6 ; \mathrm{p}<0.01\right)$ and their incomes at weekends $\left(\mathrm{Chi}^{2}=14.0 ; \mathrm{p}<0.01\right)$. On weekdays, the time spent sitting was relatively longer for younger persons (aged

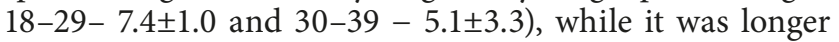
for the groups with the highest income $(3,000-4,499$ PLN/ $€ 750-1,124-5.7 \pm 2.1$ and $\geq 4,500 \mathrm{PLN} / € 1,125-6.8 \pm 1.5)$.

The health-related WHO recommendations were met by $19.1 \%$ of farmers undertaking LTPA and 19.2\% declaring transportation physical activity, whereas these were not the same persons (Transportation and LTPA 33.3\% in total). Significant factors determining realisation of the recommendations by farmers undertaking LTPA included gender $\left(\mathrm{Chi}^{2}=9.2 ; \mathrm{p}<0.01\right)$, age $\left(\mathrm{Chi}^{2}=11.6 ; \mathrm{p}<0.05\right)$, education $\left(\mathrm{Chi}^{2}=16.1 ; \mathrm{p}<0.01\right)$ and place of residence $\left(\mathrm{Chi}^{2}=13.1 ; \mathrm{p}<0.01\right)$. Thus, those who were active during leisure time were more often men (31.6 vs. $11.6 \%$ of women), persons aged $18-39$ (42.9-46.7\% vs. $15.4 \%$ - $40-49$ years; $14.3 \%$ - 50-59 years;

Table 2. Mean of MET-min/week Leisure Time Physical Activity, transportation and sitting time depending on sociodemographic factors

\begin{tabular}{|c|c|c|c|c|c|c|c|c|}
\hline \multirow[t]{2}{*}{ Factors } & & \multicolumn{3}{|c|}{$\begin{array}{l}\text { Leisure Time Physical Activity } \\
\text { (MET-min/week) }\end{array}$} & \multicolumn{2}{|c|}{$\begin{array}{l}\text { Transportation } \\
\text { (MET-min/week) }\end{array}$} & \multicolumn{2}{|c|}{$\begin{array}{l}\text { Sitting } \\
\text { (hrs/day) }\end{array}$} \\
\hline & & VPA & MPA & Walking & Cycling & Walking & Weekday & Weekend \\
\hline vericiet & Male & $7.2 \pm 125.6$ & $75.8 \pm 257.2$ & $299.4 \pm 535.8$ & $92.8 \pm 293.7$ & $382.4 \pm 622.4$ & $5.2 \pm 2.6$ & $5.2 \pm 2.6$ \\
\hline \multirow{5}{*}{ Age } & $18-29$ years old & - & $101.8 \pm 243.2$ & $527.8 \pm 317.9$ & - & $370.6 \pm 404.2$ & $7.4 \pm 1.0$ & $6.2 \pm 4.6$ \\
\hline & 30-39 years old & $27.7 \pm 204.6$ & $46.1 \pm 341.0$ & $682.4 \pm 877.9$ & $204.5 \pm 660.7$ & $656.9 \pm 1319.0$ & $5.1 \pm 3.3$ & $2.2 \pm 3.2$ \\
\hline & 40-49 years old & $43.1 \pm 152.2$ & $149.2 \pm 453.9$ & $15.9 \pm 37.1$ & $32.3 \pm 114.2$ & $319.8 \pm 1195.8$ & $2.7 \pm 1.2$ & $4.8 \pm 1.6$ \\
\hline & 50-59 years old & $17.7 \pm 160.8$ & $109.9 \pm 411.0$ & $178.8 \pm 381.3$ & $49.7 \pm 177.5$ & $537.8 \pm 1858.9$ & $4.4 \pm 2.9$ & $5.0 \pm 3.5$ \\
\hline & $>60$ years old & - & $45.8 \pm 166.5$ & $153.4 \pm 396.6$ & $54.1 \pm 237.4$ & $574.7 \pm 2447.9$ & $4.7 \pm 3.1$ & $4.3 \pm 3.4$ \\
\hline \multirow{3}{*}{ Education } & Primary & - & $31.2 \pm 130.7$ & $172.2 \pm 500.6$ & $74.1 \pm 355.7$ & $612.6 \pm 2411.2$ & $4.2 \pm 2.9$ & $4.5 \pm 3.3$ \\
\hline & Vocational & $15.7 \pm 150.7$ & $132.7 \pm 448.0$ & $200.6 \pm 403.8$ & $45.8 \pm 177.7$ & $422.4 \pm 1542.9$ & $4.5 \pm 3.1$ & $4.6 \pm 3.2$ \\
\hline & Secondary or higher & $94.2 \pm 218.8$ & $106.8 \pm 202.6$ & $431.2 \pm 490.3$ & $70.6 \pm 164.1$ & $491.5 \pm 705.4$ & $4.9 \pm 1.4$ & $3.8 \pm 3.5$ \\
\hline \multirow{2}{*}{ Place of residence } & Village & $15.5 \pm 122.6$ & $62.9 \pm 262.6$ & $182.7 \pm 465.4$ & $62.0 \pm 284.4$ & $540.4 \pm 2057.7$ & $4.4 \pm 2.9$ & $4.6 \pm 3.2$ \\
\hline & City $>50$ thous. inhabitants & - & $275.8 \pm 648.0$ & $335.9 \pm 422.6$ & $57.8 \pm 203.7$ & $311.8 \pm 443.4$ & $4.7 \pm 2.8$ & $3.2 \pm 3.4$ \\
\hline \multirow{4}{*}{ Income } & $<2,000 \mathrm{z} \nmid / \epsilon 500$ & $11.9 \pm 132.1$ & $24.0 \pm 232.3$ & $195.6 \pm 527.8$ & $23.4 \pm 137.2$ & $157.2 \pm 331.5$ & $3.6 \pm 3.6$ & $2.7 \pm 3.8$ \\
\hline & 2,000-2,999 PLN/ Є501-749 & - & $64.3 \pm 321.3$ & $200.2 \pm 418.2$ & $56.7 \pm 341.4$ & $119.4 \pm 289.2$ & $4.4 \pm 3.3$ & $4.0 \pm 3.5$ \\
\hline & 3,000- 4,499 PLN/€750-1124 & $41.5 \pm 187.9$ & $169.7 \pm 405.1$ & $223.3 \pm 546.3$ & $127.9 \pm 322.9$ & $442.4 \pm 1191.1$ & $4.9 \pm 2.2$ & $5.7 \pm 2.1$ \\
\hline & $\geq 4,500 \mathrm{PLN} / \in 1125$ & - & $37.7 \pm 149.5$ & $194.2 \pm 230.5$ & - & $2562.1 \pm 4891.5$ & $4.4 \pm 0.9$ & $6.8 \pm 1.5$ \\
\hline \multirow{3}{*}{ Using the Internet } & Regularly or occasionally & $34.3 \pm 163.6$ & $197.0 \pm 524.0$ & $201.1 \pm 527.7$ & $97.2 \pm 397.4$ & $582.4 \pm 1793.3$ & $3.8 \pm 2.1$ & $4.8 \pm 2.9$ \\
\hline & Seldom or never & $5.7 \pm 91.2$ & $32.4 \pm 142.0$ & $206.3 \pm 434.9$ & $46.8 \pm 209.9$ & $496.7 \pm 2051.6$ & $4.7 \pm 3.2$ & $4.4 \pm 3.4$ \\
\hline & Total & $14.2 \pm 117.4$ & $80.8 \pm 315.3$ & $204.8 \pm 462.4$ & $61.6 \pm 278.0$ & $521.2 \pm 1973.6$ & $4.4 \pm 2.9$ & $4,5 \pm 3,2$ \\
\hline
\end{tabular}

Bold text indicates a statistically significant correlation with a p-value less than 0.05 . 
$14.5 \%->60$ years), those with secondary or higher education (50.0\% vs. $19,7 \%$ - vocational; $12,0 \%$ - primary), and those living in cities of $>50$ thousand inhabitants $(46.2 \%$ vs. $16.4 \%$ - village). On the other hand, the likelihood of undertaking a sufficient amount of physical activity among farmers active in transportation depended significantly on their monthly incomes. The WHO recommendations were more often met by $\left(\mathrm{Chi}^{2}=8.7 ; \mathrm{p}<0.05\right)$ respondents from the highest income groups, i.e. $\geq 4,500$ PLN/€ 1,125 (21.1\%) and 3,000-4,499 PLN/€ 750-1,124 (33.3\%), compared to the groups earning 2,000-2,999 PLN/€ 501-749 (12.3\%) and <2,000 PLN/€ 500 (11.4\%).

Analysis of logistic regression revealed that the participation of farmers in LTPA increased the chance of achieving a healthy amount of physical activity by more than 12 times $(\mathrm{OR}=12.54)$ (Tab. 3). A similar situation was observed in the case of those from the transportation activity group; however, the quotient of chances was not high $(\mathrm{OR}=0.68)$.

Table 3. Association of insufficient physical activity (according to WHO recommendations) with socio-demographic characteristics and declared frequency of various forms of activity

\begin{tabular}{lcc}
\hline Factor & $\begin{array}{c}\text { Odds ratio for } \\
\text { engaging in } \\
\text { recommended } \\
\text { amount of physical } \\
\text { activity }{ }^{*} \text { OR }\end{array}$ & $\begin{array}{c}95 \% \\
\text { Confidence } \\
\text { Intervals }\end{array}$ \\
\hline Male gender & 1.93 & $0.97-3.86$ \\
\hline Age $>40$ years & $\mathbf{0 . 3 5}$ & $0.14-0.87$ \\
\hline Income $>3,000$ PLN/ 6750 & $\mathbf{3 . 1 2}$ & $1.56-6.28$ \\
\hline Secondary or higher education & 3.42 & $0.92-12.73$ \\
\hline Regularly or occasionally using the Internet & 0.76 & $0.37-1.57$ \\
\hline Participation in LTPA & $\mathbf{1 2 . 5 4}$ & $5.6-28.06$ \\
\hline Participation in transportation & $\mathbf{0 . 0 7}$ & $0.03-0.16$ \\
\hline "calculated vs. others \\
Bold text indicates a statistically significant correlation with a p-value less than & 0.05.
\end{tabular}

Along with age, the risk of too little (for health maintenance) physical activity of farmers is increasing; thus, respondents aged over 40 have a three times lower chance of being sufficiently active $(\mathrm{OR}=0.35)$ in relation to people aged $18-39$. Additionally, the chances of farmers with incomes higher than 3,000 PLN/€750 meeting the WHO norms are over 3 times bigger when compared to groups with lower incomes.

\section{DISCUSSION}

The specific nature of the farming profession, as far as undertaken physical activities and the state of occupational safety and health are concerned, often leads to serious health problems, such as aches in the back, arms and hands [18], injuries related to operating mechanical equipment, e.g. crushing or amputations of limbs [18], and diseases caused by biological factors and allergens of plant and animal origin, e.g. poisoning, lesions of the pulmonary tract, eyes and skin [19]. The Chief Labour Inspectorate [20] reports that farming is ranked as one of the leading branches of the economy with the highest incidence of occupational diseases among employees (lower only than forestry, coal-mining and metallurgy). According to the data of the Chief Labour Inspectorate [21] in 2013, 331 per 1,000 Polish farmers were at risk of strain (understood as the harmful influence of working activities on an employee, e.g. constrained posture, working in conditions of high physical effort or particular hazard). 192 of them were at risk due to an excessive physical workload (requiring energy expenditure during one shift of $8,374 \mathrm{~kJ}$ for men (2,000 kcal) and 4,605 kJ for women (1,100 kcal).

Large physical effort is a characteristic feature of the farming profession [22]. A number of researchers suggest that farmers have a higher rate of physical activity (PA) than those in other professions $[3,23]$. The PA weekly index findings indicate that the majority of farmers and their spouses meet or exceed the 2008 national PA guidelines for vigorous and muscle-strengthening activity during the growing season [24], despite the fact that there are published studies showing that only $30 \%$ of men and $21 \%$ of women were able to meet the physical activity guidelines [2]. What is essential to note is the forecast that there will be a further decrease in physical activity as a result of less labour-intensive farm work and a shorter farming season [3].

Researchers also point to serious risks for rural populations of diseases connected with obesity [25, 26], diabetes [10] and the circulatory and locomotor systems $[27,28]$, at the same time pleading for prompter responses in the field of health policy to these alarming prognoses. They particularly emphasise the importance of making health-promoting changes, including promotion of LTPA [5] and increasing the awareness of farmers concerning the benefits and the necessity of undertaking physically active ways of spending leisure time (different from everyday physical work). However, one must be aware that today's health-related education faces numerous barriers in rural societies, which are related to the underestimation of health prevention activities, a lack of infrastructure for its promotion, insufficient activity of local authorities in this field and, very often, a lack of role models in the area of healthy activities in the form of LTPA as well as qualified health prolocomotors [8, 29-31].

According to specialists, a minimal amount of physical activity during leisure time should result in energy expenditure of over 1 thousand kcal per week. It should be distributed over 4-5 days, which corresponds to moderate intensity physical training of 30-45 minutes, during which the frequency of heart systoles reaches $60-70 \%$ of the maximal frequency for a particular age.

The recommendations are more rigorous. They suggest undertaking moderate activities $\geq 150 \mathrm{~min} /$ week, intensive activities $\geq 75 \mathrm{~min} /$ week, walking $\geq 150 \mathrm{~min} /$ week, or an equivalent combination of all leisure time physical activities of over $600 \mathrm{MET}-\mathrm{min} /$ week [13].

The presented study revealed that the WHO recommendations are met by only $33.3 \%$ of respondents, even taking transportation into consideration. Only 19.1\% of farmers perform a recommended amount of activity solely by the means of LTPA. What is more, this result is the effect of mainly walking $(204.8 \pm 462.4 v s$. Moderate activity $-80.8 \pm 315.3$ and vigorous activity $-14.2 \pm 117.4$ MET-min/week) - which does not satisfy the requirements of a conscious and intentional activity. I must be noted that there is a high dispersion of results around mean values for moderate, vigorous activities and walking, indicating a large differentiation of physical activity parameters among the analysed group of farmers.

The value of walking and other transportation activities (going to work on foot or by bike) is not in question, as 
they may decrease the risk of CVD by $11 \%$, on average [32]. However, itmust be borne in mind that the preventive influence of walking increases along with its duration time and, what is more important, its intensity. According to the findings of the current study, such activity of farmers is low (582.9 $\pm 1981.2 \mathrm{MET} / \mathrm{min} /$ week), as in the case of moderate (8.7\% declared respondents) and intensive (1.8\%) activities.

A report by Kaleta et al. [33] acknowledges a common reluctance to engage in leisure time physical activity among people whose professional work is related to hard physical labour. Similar observations are expressed by other researchers $[2,5]$. However, conducted observations prove that the risk of CVD among people of high LTPA is lower by $20-30 \%$. Moderate LTPA decreases this risk by $10-20 \%$ [15]. The results of the presented studyshow that the chance to undertake physical activities within parameters recommended by the WHO are over 12 times $(\mathrm{OR}=12.54)$ higher in the case of farmers participating in LTPA.

Additionally, specialists state that LTPA as a form of movement different from everyday activities brings particular health-related benefits [34], while physical effort related to professional work (especially a large static workload) often increases the risk of various diseases, e.g. of the circulatory or locomotor systems [34, 35]. Physical activity of health-promoting parameters has an influence on decreasing ailments of the locomotor system, characteristic for particular professions [14].

Other unfavourable effects on health may be caused by sitting for a long time. Numerous data show that the longer the time of sitting (sitting or lying posture produces energy expenditure lower than resting metabolism by only $50 \%$ ), the higher the risk for health, even when one also participates in physical activity [36]. This concerns the group of farmers from the presented research group as the sitting time on weekdays in their case is $4.4 \pm 2.9$ and $4.5 \pm 3.2 \mathrm{hrs} /$ day at weekends, and these results are close to those for people with sedentary work, e.g. highly educated employees (about 5 hours) [37] and office workers (about 6 hours during a working day) [38]. When taking into consideration the youngest farmers (aged 18-29$7.4 \pm 1.0$ and $30-39-5.1 \pm 3.3$ hours on weekdays) and those with the highest incomes $(3,000-4,499$ PLN/€750-1,124-5.7 \pm 2.1 and $\geq 4500$ PLN/€1125 $-6.8 \pm 1.5$ hours at weekends), the described unfavourable phenomenon is even more prevalent. In studies by the authors, these two factors - age and income (apart from participation in LTPA and transportation), had significant importance in achieving a recommended amount of physical activity for obtaining health-related advantages. As they age, farmers' risk getting an insufficient amount of physical activity for health increases. The amount of PA is negatively correlated with age, but tends to increase for older people compared to those who are middle-aged [39]. The chance of respondents aged over 40 being active, as in other professional groups [40], is nearly 3 times lower than in the case of younger farmers. On the other hand, respondents with incomes over 3,000 PLN/€750 have an over three times greater chance of meeting the WHO norms for health-promoting physical activity than those who declare a lower income, which is also in line with current research results [41].

A comparative study between rural and urban older adults by Parks, Housemann \& Brownson found income to be a significant predictor of PA, with lower income individuals reporting a lower level of PA [42]. However, a relationship between regular or occasional use of the Internet and realising recommended physical activity was not observed, which suggests that this behaviour is not determined by that phenomenon in rural areas [43].

This paragraph should be in 'Conclusions' below:

To conclude, we may state that LTPA analysed in the presented study was determined by gender, age, education and place of residence. The most active respondents were men, aged 18-39, with secondary or higher education and living in cities of over 50 thousand inhabitants. As a result, this proves a well-known rule that the younger, more educated, and more urban-based these individuals are the lower the percentage of this group not active in LTPA [40].

\section{CONCLUSIONS}

The presented and earlier studies focused on the low engagement of Polish farmers in LTPA and their worrying frequent sedentary behaviour, which can increase the risk of cardio-vascular diseases which, nowadays, are the main cause of premature deaths. It suggests the necessity for a prompt intervention in this professional group (which is especially threatened by work hazards and harmful environmental factors). The most essential aspect is to make healthpromoting changes, including increasing the awareness of farmers concerning the benefits and the necessity of undertaking physically active forms of spending leisure time (different from everyday physical work).

Programmes developed for the popularisation of leisuretime health, promoting physical activity for farmers, should be adjusted to local communities. Considering the fact that the most popular form of physical activity among respondents was walking, it seems legitimate to develop a local tourist trail, bike lanes and open-air gyms as forms and means of promoting physical activity also among women, persons aged over 40 and people from groups of lower income, who are particularly threatened by inactivity. What is more, there is a need for the further monitoring of physical activity (including its level and determinants). Another crucial step is the diagnosis and evaluation of all types of activities (farming work, housework, during leisure time and transportation), including measurement of their time, frequency and intensity, and the pace and distance using both objective as well as subjective research tools.

Strengths and limitations of the study. This work contains the latest research results (2014-2015) which, for the first time, prove that the leisure time physical activity of Polish farmers is too low. The study was carried out using the standardised tool of the International Physical Activity Questionnaire. This tool is widely used in population-based studies because it is characterised by relatively high reliability, and its use is much less expensive than the use of tools that measure the physical activity directly. Farmers aged over 18 were selected out of a representative sample of Polish society.

Due to the fact that the research made use of the IPAQ, estimation of leisure time physical activity was based on the data declared by the respondents. The results point to a need to conduct further research which would evaluate the physical activity of farmers in other areas of their daily activity, i.e. during their work in the field, around the farm and in the house. This kind of information would provide a full picture of physical activity in this professional group. 


\section{Acknowledgement}

The research was commissioned by the Ministry of Sport and Tourism of the Republic of Poland and carried out by the Institute GfK Polonia in Warsaw.

\section{Ethics Committee Approval}

The study was carried out with the approval No. n/2012 of the University Bioethics Committee for Scientific Research of 13 December 2012 at the Jerzy Kukuczka Academy of Physical Education in Katowice, Poland.

\section{REFERENCES}

1. Perkiö-Mäkelä M. Influence of Exercise-Focused Group Activities on the Physical Activity, Functional Capacity, and Work Ability of Female Farmers - A Three-Year Follow-Up. Int J Occup Saf Ergon. 1999; 5(3): 381-94. https://doi.org/10.1080/10803548.1999.11076427

2. Koh C. Fact Sheet 26. Physical Activity in Rural Australia. National Rural Health Alliance ISC, 2011. http://ruralhealth.org.au/sites/default/ files/fact-sheets/Fact-Sheet-26-physical\%20activity\%20in\%20rural\%20 australia_0.pdf (access: 2015.11.24)

3. Ding D, Sallis JF, Hovell MF, et al. Physical activity and sedentary behaviors among rural adults in Suixi, China: a cross-sectional study. Int J Behav Nutr Phy. 2011; 8: 37.

4. CDC. Self-reported physical inactivity by degree of urbanizationUnited States, 1996. MMWR Morb Mortal Wkly Rep. 1998; 47: 1097-100.

5. Schwantes T. Using Active Living Principles to Promote Physical Activity in Rural Communities. Presentation at the 2010 Active Living Research Annual Conference. Active Living Research. Promoting activity-friendly communities, 2010. http://activelivingresearch. org/using-active-living-principles-promote-physical-activity-ruralcommunities (access: 2015.11.24)

6. Yousefian A, Ziller E, Swartz J, Hartley D. Active Living for Rural Youth: Addressing Physical Inactivity in Rural Communities. J Public Health Manag Pract. 2009; 15(3): 223-231.

7. Joens-Matre RR, Welk GJ, Calabro MA, et al. Rural-urban differences in physical activity, physical fitness, and overweight prevalence of children. J Rural Health. 2008; 24(1): 49-54.

8. Wilcox S, Castro C, King AC, et al. Determinants of leisure time physical activity in rural compared with urban older and ethnically diverse women in the United States. J Epidemiol Community Health. 2000; 54: 667-672.

9. Muntner P, Gu D, Wildman RP, et al. Prevalence of physical activity among Chinese adults: results from the International Collaborative Study of Cardiovascular Disease in Asia. Am J Public Health. 2005; 95(9): 1631-1636.

10. Brumby S, Chandrasekara A, McCoombe S, et al. Reducing psychological distress and obesity in Australian farmers by promoting physical activity. BMC Public Health. 2011; 11: 362.

11. Olsen O, Kristensen TS. Impact of work environment on cardiovascular diseases in Denmark. J Epidemiol Community Health. 1991; 45(1): 4-9.

12. Ruzic L, Heimer S, Misigoj-Durakovic M, Matkovic BR. Increased occupational physical activity does not improve physical fitness. Occup Environ Med. 2003; 60: 983-985.

13. WHO. Global Recommendations on Physical activity for Health 2010 http://whqlibdoc.who.int/publications/2010/9789241599979_eng.pdf (access: 2014.12. 22)

14. Mynarski W, Grabara M, Nawrocka A, et al. Physical recreational activity and musculoskeletal disorders in nurses. Med Pr. 2014; 65: 181-188.

15. Holtermann A, Marott JL, Gyntelberg F, et al. Does the Benefit on Survival from Leisure Time Physical Activity Depend on Physical Activity at Work? A Prospective Cohort Study. PLoS ONE. 2013; 8(1): e54548.

16. Drygas W, Kwaśniewska M, Kaleta D, et al. Epidemiology of physical inactivity in Poland: Prevalence and determinants in a former communist country in socioeconomic transition. Public Health. 2009; 123(9): 592-597.

17. Biernat E. International Physical Activity Questionnaire - Polish long version. Polish J Sport Med. 2013; 29(1): 1-15.

18. Holmberg S, Thelin A, Stiernstrom E, Svardsudd K. The impact of physical work exposure on musculoskeletal symptoms among farmers and rural non-farmers. Ann Agric Environ Med. 2003; 10(2): 179-184.
19. Op De Beeck R, Hermans V. Work-related Low Back Disorders. Report. Institute for Occupational Safety and Health. European Agency for Safety and Health at Work. Luxembourg 2000. https://osha.europa.eu/ en/tools-and-publications/publications/reports/204 (access: 2015.11.24)

20. Państwowa Inspekcja Pracy /National labour Inspectorate. Główny Inspektorat Pracy /Chief Labour Inspectorate. Work conditions in agriculture, particularly in terms of job safety. Material for Labour Protection Council meeting on 18 February 2004. Warsaw - February 2004. In Polish

21. CSO. Work conditions in 2013. Warsaw: Central Statistical Office. http:// stat.gov.pl/obszary-tematyczne/rynek-pracy/warunki-pracy-wypadkiprzy-pracy/warunki-pracy-w-2013-r-,1,8.html (access: 2015.11.24).

22. Pan SY, Ugnat AM, Mao Y. Physical activity and the risk of ovarian cancer: a case-control study in Canada. Int J Cancer. 2005; 117(2): 300-307.

23. Krishnadasan A, Kennedy N, Zhao Y, et al. Nested case-control study of occupational physical activity and prostate cancer among workers using a job exposure matrix. Cancer Causes Control. 2008; 19(1): 107-114.

24. Racine EF, Laditka SB, Dmochowski J, et al. Farming Activities and Carrying and Lifting: The Agricultural Health Study. J Phys Act Health. 2012; 9(1): 39-47.

25. Brumby S, Chandrasekara A, McCoombe S, et al. Farming fit? Dispelling the Australian agrarian myth. BMC Research Notes. 2011; 4(1): 89.

26. Bergier J, Bergier B, Tsos A. Place of residence as a factor differentiating physical activity in the life style of Ukrainian students. Ann Agric Environ Med. 2016; 23(4): 549-552.

27. Bourke L. Toward understanding youth suicide in an Australian rural community. Soc Sci Med. 2003; 57(12): 2355-65.

28. Janus ED, Laatikainen T, Dunbar JA, et al. Overweight, obesity and metabolic syndrome in rural southeastern Australia. Med J Aust. 2007; 187(3): 147-52.

29. Charzyńska-Gula M, Sygit K, Sygit M, et al. Chair of Oncology and Environmental Health Care, Problems of health education in rural areas in Poland. Ann Agric Environ Med. 2013; 20(3): 515-522.

30. Bauman AE; Reis RS, Sallis JF, et al. Correlates of physical activity: why are some people physically active and others not? Lancet. 2012; 380(9838): 258-71. doi:10.1016/S0140-6736(12)60735-1.

31. Carroll S, van Kessel G, Gill R, et al. Comparisons of barriers and enablers of leisure-time physical activity between farm and town residents in a rural Australian region. Obes Res Clin Pract 2011; 5 Suppl.(1): 30 .

32. Hamer M, Chida Y. Active commuting and cardiovascular risk: a meta-analytic review. Prev Med. 2008; 46(1): 9-13.

33. Kaleta D, Makowiec-Dąbrowska T, Jegier A. Lifestyle Index and Work Ability. Int J Occup Med Environ Health. 2006; 19(3): 170-177.

34. Makowiec-Dąbrowska T. Wpływ aktywności fizycznej w pracy i życiu codziennym na układ krążenia / The impact of physical activity at work and everyday life on the cardiovascular system/. Forum Med. Rodz. 2012; 6(3): 130-138.

35. Puciato D, Rozpara M, Mynarski W, et al. Physical activity of adult residents of Katowice and selected determinants of their occupational status and socio-economic characteristics. Med Pr. 2013; 64(5): 649-657.

36. Katzmarzyk PT, Church TS, Craig CL, Bouchard C. Sitting time and mortality from all causes, cardiovascular disease, and cancer. Med Sci Sports Exerc. 2009; 41(5): 998-1005.

37. Wallmann-Sperlich B, Bucksch J, Schneider S, Froboese I. Sociodemographic, behavioural and cognitive correlates of work-related sitting time in German men and women. BMC Public Health. 2014; 14: 1259.

38. Ryde GC, Helen EB, Peeters GME, et al. Desk-Based Occupational Sitting Patterns. Am J Prev Med. 2013; 45(4): 448-452.

39. Biernat E, Bartkiewicz P, Buchholtz S. Are structural changes in Polish rural areas fostering leisure-time physical activity? Int J Environ Res Public Health. 2017; 14:372; doi:10.3390/ijerph14040372

40. Biernat E, Tomaszewski P. Association of socioeconomic and demographic factors with physical activity of males and females aged 20-69 years. Ann Agric Environ Med. 2015; 22(1): 118-123.

41. van Lenthe FJ, De Bourdeaudhuij I, Klepp KI, et al. Preventing socioeconomic inequalities in health behaviour in adolescents in Europe: background, design and methods of project TEENAGE. BMC Public Health. 2009; 9: 125.

42. Parks SE, Housemann RA, Brownson RC. Differential correlates of physical activity in urban and rural adults of various socioeconomic backgrounds in the United States. Br Med J. 2003; 57(1): 29.

43. Healy GN, Wijndaele K, Dunstan DW, et al. Objectively measured sedentary time, physical activity, and metabolic risk: the Australian Diabetes, Obesity and Lifestyle Study (AusDiab). Diabetes Care. 2008; 31(2): 369-371. 